\title{
SISTEMA JURÍDICO DA R.E.D.D NA CAATINGA PERNAMBUCANA
}

\author{
Afonso Feitosa Reis Neto \\ Doutorando em Desenvolvimento e Meio Ambiente (PRODEMA/UFPE).Mestre em \\ Desenvolvimento e Meio Ambiente (PRODEMA/UFPE). Bacharel em Direito pela UFPE. \\ Tecnólogo com láurea em Gestão Ambiental pelo IFPE. Professor do Instituto Federal de Edu- \\ cação, Ciência e Tecnologia do Piaú (IFPI). Líder do Grupo de Pesquisa/CNPQ - Laboratório \\ Interdisciplinar Sociedade, Ambiente e Direito (LISA-D). Advogado (OAB/PE). \\ Email: afonsofeitosa@hotmail.com \\ Leônio José Alves da Silva \\ Pós-Doutor em Direito pela Faculté de Droit et de Science Politique - Université Montpellier \\ - França.Pós-Doutor em Direito pela Faculdade de Direito da Universidade de Coimbra, \\ Portugal. Pós-Doutor em Direito pela Universitàdegli Studi di Messina - Itália. Professor As- \\ sociado da Faculdade de Direito do Recife (UFPE). Professor do Programa de Pós-graduação \\ em Desenvolvimento e Meio Ambiente (UFPE) \\ Email: leonioalves@bol.com.br \\ Maria do Socorro Bezerra de Araújo \\ Pós-doutorado pela School of Environmental Sciences, University of Guelph, Canadá (2010). \\ Doutorado em Agronomia (Solos e Nutrição de Plantas) pela Universidade Federal de Viçosa \\ (2000). Professora Associado II da Universidade Federal de Pernambuco e Membro do \\ Programa em Rede de Pós-graduação em Desenvolvimento e Meio Ambiente. \\ Email: socorror@ufpe.br
}

\begin{abstract}
RESUMO
O estado de Pernambuco sofre os diversos efeitos das mudanças climáticas. Uma das ações antrópicas que contribuem para esse quadro éo desmatamento da vegetação do bioma Caatinga. Almejando conciliar a proteção das vegetações nativas e minimização das ações que contribuem para o efeito estufa, aflora no cenário internacional o instrumento denominado Redução do Desmatamento e da Degradação Florestal (R.E.D.D). A R.E.D.D é uma espécie de Pagamento por Serviços Ambientais (PSA), que possui como fundamento o princípio do Direito Ambiental denominado protetor-recebedor. Assim, o presente estudo buscou caracterizar os aspectos legais para a efetivação no estado de Pernambuco. Para tanto, analisaram-se os diplomas legais e publicações (oficiais e extraoficiais) relativos à concretização desse modelo na esfera estadual. Os resultados demonstram que é possível a implantação do instrumento em Pernambuco,
\end{abstract}


pois, nesse estado, existe todo um arcabouço legal criado para efetivação do instrumento, que vai desde a definição de responsabilidades até o desenvolvimento de um arranjo institucional.

Palavras-chave: Pagamentos por Serviços Ambientais; Carbono; Mudanças Climáticas; Pernambuco.

\title{
LEGAL SYSTEM OF R.E.D.D IN CAATINGA OF PERNAMBUCO
}

\begin{abstract}
The State of Pernambuco undergoes the various effects of climate change. One of the anthropic actions that contribute tothis situation is the deforestation of the vegetation in Caatinga biome. Aiming to reconcile the protection of native vegetation and minimization of actions that contribute to the greenhouse effect, the instrument called Reduction of Deforestation and Forest Degradation (R.E.D.D) appears in the international scenario. The R.E.D.D is a type of Payment for Environmental Services (PES) based on the principle of Environmental Law called protector-receiver. Thus, the present studys ought to characterize the legal aspects for effectiveness in Pernambuco. For that, we analyzed the laws and publications (official and non-official) related to the implementation of this model at the state level. The results demonstrate that it is possible to implement the instrument in Pernambuco, because in the State there is a legal framework created to impleme the instrument ranging from the definition of responsibilities to the development of an institutional arrangement.
\end{abstract}

Keywords: Payment for Environmental Services; Carbon; Climate Changes; Pernambuco. 


\section{INTRODUÇÃO}

A situação de Pernambuco é um case interessante para análise quanto à vulnerabilidade ocasionada pelos efeitos da mudança do clima e à importância de uma legislação estadual que se adeque à situação do ente federado em destaque. Este estado possui superfície territorial de, aproximadamente, $98.146 \mathrm{~km}^{2}$, abrigando uma grande diversidade de ecossistemas. Cerca de 8 mil espécies de organismos foram registradas e, como muitos grupos ainda não foram estudados, estima-se que este número varie entre 24 mil e 90 mil. Tamanha diversidade biológica contrasta com os altos níveis de degradação dos ecossistemas da Mata Atlântica e da Caatinga, com $12 \%$ e $50 \%$ da sua cobertura original respectivamente (PERNAMBUCO, 2011; S.O.S MATA ATLÂNTICA, INPE, 2015).

As regiões do Agreste e Sertão, locais em que a Caatinga é predominante, apresentam grande pressão antrópica sobre os recursos naturais, especialmente os florestais. A ação do homem processa-se com intensidade, resultando em áreas degradas pelo consumo da lenha e pelo intenso processo de urbanização tanto na Região Metropolitana quanto nos outros polos econômicos, como a região do Araripe (PERNAMBUCO, 2011).

É evidente o passivo ambiental acumulado que incide sobre o estado, sendo considerado, pelo Painel Intergovernamental sobre Mudanças Climáticas - IPCC, um "hotspot" mundial em relação às alterações do clima. Enquanto na área litorânea se intensifica o processo erosivo nas praias, com ameaça iminente ao patrimônio público e privado, a região do Sertão e Agreste padece do fenômeno das secas, juntamente com o processo de desertificação, fato que potencializa o surgimento de grupos denominados refugiados e/ou deslocados ambientais (AMORIM; BARROS, 2017).

No interior, de acordo com os critérios nacionais, Pernambuco possui 135 municípios nas áreas suscetíveis à desertificação (ASD), onde vivem, segundo o censo demográfico de 2000, 2.622 .519 milhões de habitantes, conformando uma densidade demográfica de $35,34 \mathrm{hab} / \mathrm{km}^{2}$. Este quadro poderá levar a processos migratórios, deslocando as populações afetadas para os centros urbanos, sobrecarregando os serviços nesta região e agravando ainda mais a condição socioeconômica (PERNAMBUCO, 2011).

A Política Estadual de Enfrentamento às Mudanças Climáticas 
de Pernambuco (PEEMC/PE) revela-se como o principal instrumento do Governo Estadual para combater as alterações do clima. Publicada em 2010, tal ação pode ser entendida como uma resposta à fragilidade que o estado possui frente às modificações, tendo em vista que consequências são sentidas em diversas regiões. Como resultado, Pernambuco ganhou uma série de programas voltados para as mudanças climáticas e ampliou o orçamento de outros já existentes na esfera ambiental.

Dentre esses instrumentos desenhados pela PEEMC está a Redução do Desmatamento e Degradação Florestal (R.E.D.D). Criado no âmbito internacional na denominada Conferência das Partes (COPs), esse mecanismo baseia-se na concepção de Pagamento por Serviços Ambientais (PSA) e visa, através de incentivos de mercado (créditos de carbono), conter as taxas crescentes de redução da área florestal, tomando como base áreas nativas remanescentes na paisagem (ANGELSEN, 2008).

A principal diferença entre a REDD e os outros instrumentos desenvolvidos até hoje que trabalham com o tema das mudanças climáticas é que, no primeiro, existe, em teoria, a inclusão socioambiental de populações que comumente são marginalizadas nas discussões e nas tomadas de decisão acerca da conservação dos biomas naturais (GRAINGER; OBERSTEINER, 2011). Ademais, possui como um dos seus cernes a manutenção da vegetação nativa, aspecto esse que diretamente traz a lume a discussão sobre o valor (econômico e político) da floresta "em pé" (HAYES; PERSHA, 2010).

Além disso, o Art. $4^{\circ}$ da Política Nacional de Mudanças Climáticas (PNMC) prevê o fortalecimento das remoções antrópicas por sumidouros de gases do efeito estufa no território nacional, bem como a conservação e a recuperação dos recursos ambientais, sobretudo os grandes biomas naturais, tornando ainda mais valorosas as iniciativas que buscam examinar o funcionamento dos mecanismos de captação de gases do efeito estufa (GEEs) (MORAIS et al, 2016).

Destarte, posto este quadro, o presente artigo apresenta como objetivo analisar a estrutura legal para efetivação da REDD na Caatinga de Pernambuco. Ademais, como substrato teórico para discussão, será feito um breve exame da PEEMC/PE e da Política Estadual de Pagamentos por Serviços Ambientais, com base na legislação e na doutrina do Direito Ambiental, buscando sempre um diálogo interdisciplinar. 


\section{CONSIDERAÇÕES METODOLÓGICAS}

Para obtenção do objetivo proposto foi feita análise dos mais variados diplomas legais que podem ser utilizados como base para a implantação da REDD em Pernambuco. Nesse sentido, as principais fontes de consulta foram as regulamentações, tanto na seara nacional quanto na estadual. No âmbito nacional, a investigação teve como fonte as publicações oficiais provenientes do Ministério do Meio Ambiente (MMA) e do Ministério de Ciência, Tecnologia e Inovação do Brasil (MCTI).

$\mathrm{Na}$ esfera estadual foram analisadas a Lei Estadual $\mathrm{n}^{\circ} 14.090 / 10$ (Política Estadual de Enfrentamento das Mudanças Climáticas), juntamente com seu plano, e a Lei Estadual n ${ }^{\circ}$ 15.809/16 (Política Estadual de Pagamento por Serviços Ambientais). Com isso, buscou-se enfatizar, dentre as legislações apresentadas, os principais aspectos que favorecem, ou ao menos possibilitam, a concretização do instrumento no aspecto político-legal. Cabe a advertência de que não se pretende exaurir a análise das legislações em todos os seus aspectos, mas somente naquilo que pode ser utilizado como fundamentação para instauração da REDD.

Dessa maneira, a avaliação da Política Estadual de Enfrentamento às Mudanças Climáticas de Pernambuco foi iniciada com a análise do texto da norma. Por meio desta, busca-se vislumbrar a existência de um balanço entre as ações de adaptação e mitigação às mudanças climáticas. Para tanto, foram explorados desde os princípios que norteiam a política até os objetivos que se buscam e os instrumentos estabelecidos para alcançálos. Esses elementos foram confrontados com o que se observa das ações previstas e realizadas pelo poder público, para avaliar se os princípios e objetivos condizem com o realizado e, desta forma, analisar se a política está servindo como um guia para as ações públicas.

Em relação à Política Estadual de Pagamento por Serviços Ambientais (PEPSA) foram identificados seus objetivos assim como o arranjo institucional criado pela lei, os instrumentos propostos e as áreas suscetíveis (requisitos) de receber projetos de PSA Carbono. Cabe acentuar que, como o enfoque da pesquisa é referente ao REDD, somente foram examinados os tópicos que possuem relação com essa temática, deixando para o futuro o estudo e a análise da íntegra da Política. 


\section{RESULTADOS E DISCUSSÃO}

\subsection{Pagamento por Serviços Ambientais (PSA): Princípio do Protetor- Recebedor}

Quando se pensa na relação entre economia e meio ambiente, a primeira ilação que se faz é de antagonismo, ou seja, coisas opostas e incomunicáveis. Certamente, uma consequência arraigada no modelo econômico baseado na incessante busca pelo lucro selvagem que despreza a relação dos sistemas econômicos e naturais, além de não considerar a existência de limites ecossistêmicos.

Não obstante, a natureza é a base da economia, na medida em que fornece matérias-primas para serem transformadas e circuladas em forma de mercadoria. Ocorre que, paradoxalmente, a lógica de produção capitalista incentiva/permite uma apropriação irracional e suicida dos recursos.

A teoria para esse paradoxo foi muito bem descrita no texto The Tragedy of Commons de Garret Hardin, pois, de fato, a maximização racional do interesse individual sobre bens ambientais que, em tese, não podem ser exclusivos e rivais, coloca em risco a existência do próprio bem, que, não por mera coincidência, é essencial à manutenção da própria vida. No entanto, essa aspiração sem nenhum tipo de regramento pode vir a causar, e já está causando, uma série de consequências negativas para a humanidade, que vão desde o exaurimento dos recursos não renováveis até o aumento da temperatura na Terra.

Por conseguinte, de acordo com os ensinamentos de Nusdeo (1975), os problemas ambientais são reais e graves, porém, não justificam reações meramente emocionais do tipo "crescimento zero". Para o autor, a única atitude lúcida corresponde à internalização dos custos sociais da deterioração ambiental no circuito econômico. A dicotomia (natureza x economia) justificou-se enquanto os recursos naturais pareciam inesgotáveis, pois, de fato, não havia previsibilidade de escassez.

Dado que o consumo foi dissipando aceleradamente esses recursos, a preocupação com as bases naturais passou a ser necessária; porém, as dificuldades de governança dos bens comuns (ar, águas e biodiversidade por exemplo) provocou uma preocupação, pois o esgotamento destes e a saturação dos serviços ambientais tornou-se cada 
vez mais palpável.

Assim, a harmonização entre economia e ecologia tornouse condição sine qua non para a sobrevivência da própria economia e, consequentemente, da humanidade. Constanza (1991) afirma que os tradicionais modelos e conceitos econômicos, além dos ecológicos, deixam a desejar na sua capacidade de lidar com problemas globais.

Conforme citado alhures, essa relação é fundamental para compreensão da heterogeneidade das situações na humanidade, bem como para construção de um futuro sustentável; contudo, essa relação não se encaixa em nenhuma disciplina científica existente. Martínez-Alier (2007) sugere, em razão dessa lacuna epistêmica, a necessidade de uma "orquestração de ciências" comportando diversidade de pensamentos, quadro este que é amplamente difundido com o desenvolvimento da inter e/ou transdisciplinaridade. Posto esse quadro, é justamente nesse cenário complexo que emergiu e ganhou notoriedade nos últimos anos o Direito Ambiental como ramo da Ciência Jurídica, que tem como propósito a proteção/gerenciamento dos recursos ambientais.

Em termos gerais, os instrumentos albergados pelo Direito Ambiental podem ser de duas matizes: (i) comando e controle ou (ii) econômicos. Em resumo, os primeiros são as regras postas que, em tese, captando os valores da sociedade, definem limites da atuação do homem, em especial da economia. Atuam com forte presença do denominado poder de polícia estatal, tendo em vista que limitam as liberdades individuais em prol do bem-estar coletivo. Entretanto, ao longo da jornada pela implementação da proteção ambiental, percebeu-se que a simples proibição de desmatamento, por exemplo, não era suficiente para frear a pressão econômica sobre as florestas.

Desse modo, buscaram-se instrumentos econômicos capazes de complementar os limites das ferramentas de comando e controle, por meio de incentivos financeiros. No entanto, a concretização de um desenvolvimento verdadeiramente sustentável exige a utilização equilibrada de instrumentos de comando e controle, juntamente com mecanismos econômicos. Nesse quadro, emerge o Pagamento por Serviços Ambientais (PSA).

Seguindo essa abordagem, antes de trabalhar com a perspectiva do PSA, faz-se mister definir o que vêm a ser os Serviços Ambientais, também denominados por alguns autores como Serviços Ecossistêmicos. Lederer (2011) define os serviços ecossistêmicos como processos cujos 
ecossistemas naturais e as mais variadas espécies que o formam são capazes de sustentar e fornecer condições necessárias para manutenção da vida na Terra.

No mesmo sentido, Ollivier. (2012) apresenta definição sobre os serviços ecossistêmicos, caracterizando-os como as contribuições prestadas pelos ecossistemas ao bem-estar humano, estando este em forma de mercadorias, tais como alimentos e água doce, ou serviços, como a redução de enchentes e sequestro de carbono.

É justamente com o intuito de resguardar esses serviços ecossistêmicos que foram desenvolvidos mecanismos legais albergados pelo Direito, mais especificamente na seara ambiental, por meio de suas normas e, sobretudo, pelos seus princípios. Nusdeo (2012) afirma que a fundamentação do pagamento para o cumprimento de deveres legais parte de um argumento mais pragmático, como o da ausência de efetividade dos instrumentos de comando e controle, mas passa por argumentos principiológicos, como a noção do protetor-recebedor, que enfatiza os benefícios da conservação para a coletividade, ainda que decorrente de práticas determinadas legalmente.

O alicerce ontológico do PSA é baseado no princípio denominado protetor-recebedor, que propõe o pagamento àqueles agentes cuja ação promove o incremento dos serviços ambientais prestados pela natureza. Segundo Nusdeo (2012) e Sirvinskas (2017), trata-se de um verdadeiro mecanismo de internalização das externalidades positivas.

O novel princípio é sempre analisado em contraposição ao consolidado princípio do poluidor-pagador, que também consiste, em última análise, na assimilação e consequente internalização pelo sistema produtivo das chamadas externalidades negativas (falhas de mercado). Aliás, na visão de Milaré (2013), para a efetiva internalização, todas as externalidades ambientais deverão produzir objetivamente condições que não permitam que ao operador econômico seja mais vantajoso poluir do que implementar medidas de prevenção.

Nessa perspectiva, o Direito (com a indispensável ajuda da Biologia e da Economia) é o arcabouço sociopolítico que regula a vida em sociedade e, consequentemente, a relação desse corpo social com o meio em que vive, através de suas instituições, com a finalidade de empreender proteção ao bem ambiental, de forma direta ou indireta.

Assim como o sistema jurídico, holisticamente considerado, deve ser sustentável, suas instituições devem ser pensadas ou criadas seguindo 
a mesma lógica, ou seja, deve-se, primeiramente, criar um ambiente ou campo institucional que seja capaz de absorver e harmonizar as regras da sociedade, de maneira a ser perfeitamente encaixada nas engrenagens do ecossistema, mas que, ao mesmo tempo, seja capaz de ser modificada de acordo com os interesses da sociedade que regula. Dessa necessidade de renovação dos instrumentos de gestão ambiental surge o PSA. Assim, o Direito passa a assumir um papel de promotor do comportamento ecologicamente adequado e não apenas repressor do inadequado.

O pagamento por serviços ambientais é uma das principais ferramentas desenvolvidas pela economia ambiental para concretizar a ideia de internalização da natureza na função de produção. Para Wunder (2005), o PSA é uma transação voluntária através da qual um serviço ecológico específico é adquirido por um (ou mais) adquirentes de um (ou mais) provedor do serviço ambiental, se, e somente se, o provedor do serviço assegurar sua provisão. Logo, observam-se cinco requisitos: (i) um serviço ecológico específico; (ii) um adquirente; (iii) um provedor; (iv) a obrigatoriedade de provisão do serviço e (v) transação voluntária.

Em síntese, elege-se um único serviço ambiental, provido por um proprietário/garantidor que se obriga a provê-lo em troca de um pagamento, não necessariamente financeiro. Contudo, o desenvolvimento da ciência ecológica revela que a interação entre o funcionamento dos ecossistemas e os benefícios que eles proporcionam à sociedade exige uma visão sistêmica e interdisciplinar dos instrumentos econômicos. Não por acaso, o estudo da estrutura legal do PSA e, consequentemente, da REDD, é ontologicamente heterogêneo no que cabe às suas fontes de informação.

As funções prestadas pelos ecossistemas, que a posteriori são valoradas, são as constantes interações existentes entre seus elementos estruturais, incluindo transferência de energia, ciclagem de nutrientes, regulação de gás, regulação climática e do ciclo da água, estocagem de carbono, entre outros (DALY; FARLEY, 2004). Portanto, os ecossistemas não são formados apenas por espécies individualmente consideradas, tais como, árvores, animais, água, minérios, entre outros.

Para uma análise holística e de maior credibilidade, devem ser considerados os fluxos de energia e matéria que sustentam essas complexas interações, ou seja, suas funções significantemente sensíveis à ação humana. Essas funções, quando vistas sob o ponto de vista de sua utilidade para a humanidade são chamadas de serviços. Todavia, de acordo com Boyd e Banzhaf (2007) nem sempre essas funções estabelecem uma 
relação direta com um serviço, ou seja, um único serviço ecossistêmico pode ser o produto de duas ou mais funções, ou uma única função pode gerar mais que um serviço ecossistêmico. Ademais, há que se observar que essa relação entre bens e funções pode se dar em várias escalas espaciais e temporais, o que torna sua compreensão e análise uma tarefa ainda mais complexa

Necessita-se, pois, em última análise, conforme aduz Cunha (2015), uma reformulação do próprio conceito de PSA, que passa a ser implementado não apenas com intuito de preservar ou recuperar um único serviço ambiental, mas sim um determinado ecossistema, assim considerado como um conjunto de processos físicos, químicos e biológicos.

Uma visão complexa dos serviços ambientais, evidentemente, dificulta a sua compreensão, visto que se identificam uma miríade de processos interligados e correlacionados. Essa dificuldade mostra-se ainda mais difusa quando se pensa em mecanismo que deve levar em consideração essas interações e, ao mesmo tempo, assegure sua proteção contra a pressão da economia. Sem uma metodologia transdisciplinar, não há como se concretizar um desenvolvimento sustentável.

Muradian et al (2010) defendem uma redefinição do conceito de PSA, trazendo uma abordagem mais ampla de serviços da natureza, levando em consideração, inclusive, fatores socioculturais na implementação dos programas. Contudo, essa complexidade se reflete no aspecto jurídico, que passa a exigir um desenho institucional, que, adequando-se à variabilidade das características locais, favoreça a manutenção ou recuperação da qualidade ambiental, ao mesmo tempo que propicie o desenvolvimento econômico e social de determinada localidade, o que se mostra fundamental para regular o funcionamento do papel de flexibilização do Direito.

Em alguns casos, como na Costa Rica, criou-se um verdadeiro arranjo institucional no âmbito nacional para sua implementação, com uma íntima relação entre o sistema jurídico e disciplinas como a Biologia e a Economia; contudo, há casos, como no Brasil, em que, mesmo sem um marco legal nacional e uma cambialidade disciplinar, é possível identificar experiências estaduais e até mesmo locais.

Uma crítica que merece reverberar é proposta por MartínezAlier (2007), apoiado por Contanza (1991), na qual reside a denominada incomensurabilidade dos bens e serviços ambientais. De fato, a simples valoração e internalização dos bens ambientais à função de produção, como defendem os economistas ambientais, não é suficiente para corrigir 
as imperfeições da Economia.

Vale salientar que diversos métodos de valoração são até factíveis, sendo aplicáveis em diversos países, inclusive no Brasil; mas, a tentativa de objetividade e interdisciplinaridade eleva significativamente os custos de transação que tornam alguns métodos inviáveis economicamente e com sérias restrições técnicas. Todavia, nada impede a elaboração de experiências, modelos, artigos e livros que tragam a lume a vivência dessas ações, enriquecendo mais ainda o patrimônio intelectual daqueles que se interessam pelo estudo do PSA.

Ainda sob esta ótica, trazendo à baila mais especificamente os serviços ambientais florestais e, em atenção às novas metodologias de quantificação de PSA, surge a REDD, que prevê a compensação financeira àqueles que evitam ou reduzem emissões, desmatamento e degradações. Esses programas enquadram-se perfeitamente na ideia de PSA, pois a manutenção das florestas "em pé”, que nos oferecem inúmeros serviços, propicia a sustentação dos fluxos e recursos essenciais para o equilíbrio ecológico.

\subsection{Política Estadual de Enfrentamento às Mudanças Climáticas (Lei Estadual no 14.090/10)}

A Política Estadual de Enfrentamento às Mudanças Climáticas (Lei Estadual no 14.090/10) traz em seu escopo a apresentação-padrão para as normativas ambientais brasileiras: conceitos, objetivos, e instrumentos. Tal formatação, de acordo com Milaré (2013), revela o intuito de facilitar o acesso da população em geral ao conteúdo da norma. Além desses elementos, apresenta também o capítulo denominado "Estratégias de mitigação e adaptação", buscando, com isso, pormenorizar os campos de atuação da legislação.

Não obstante o caráter pedagógico apresentado pela lei, o seu conteúdo, logo na apresentação conceitual, presente no art. $1^{\circ}$ e incisos, demonstra sua atualidade perante os principais acordos e convenções concernentes às alterações climáticas. Expressões como MDL (Mecanismo de Desenvolvimento Limpo), REDD (Redução do Desmatamento e da Degradação Florestal) e mercado de carbono estão presentes. O objetivo geral é apresentado da seguinte maneira: 
Art. $2^{\circ}$ A Política Estadual de Enfrentamento à Mudança do Clima tem por objetivo garantir à população que o Poder Público promova os esforços necessários para aumentar a resiliência da população pernambucana à variabilidade e às mudanças climáticas em curso, bem como contribuir com a redução das concentrações dos gases de efeito estufa na atmosfera, em níveis não danosos às populações e aos ecossistemas, assegurando o desenvolvimento sustentável (PERNAMBUCO, 2010).

Pela leitura inicial do caput, percebe-se prima facie que o Poder Público traz para si a responsabilidade para a implementação da Política Estadual. De acordo com Fiorillo (2014), tal postura, em matéria ambiental, não é a mais adequada a ser adotada. O autor argumenta, de maneira correta, que, no concernente ao meio ambiente, a responsabilidade deve ser dividida perante a sociedade e a iniciativa privada, além do Poder Público, na medida das possibilidades institucionais e legais. Para tanto, traz como exemplo o texto da Constituição Federal de 1988, no seu art. 225, em que fica clara (e explícita) a intenção do legislador constituinte, acerca da incumbência imposta ao Poder Público e à coletividade quanto ao dever de defender e preservar o ambiente para as presentes e futuras gerações (BRASIL, 1988).

É vital destacar que, assumindo uma interpretação conforme à Constituição e baseado na hermenêutica compatível com a matéria ambiental, o objetivo geral da lei pernambucana não exime a coletividade e as empresas de assumirem a postura pro natura no que se refere às mudanças climáticas. Sem dúvida, perde-se a oportunidade de concretizar, de maneira expressa, tal relação. Ost (2015) aduziu que, além de um impacto moral e político, a corporificação legal das temáticas ambientais, nesse caso das alterações climáticas, abre uma gama de benefícios de diversas ordens, propiciando um impacto fático na (re)organização do relacionamento da sociedade e do Poder Público.

Rothenburg (2005) considerou que a mera menção em textos normativos tem uma importância destacada, pois evidencia o valor do ambiente e firma um compromisso de implementação com os envolvidos. Todavia, seria utópico pensar que somente com o agasalho da lei o clima estaria protegido, já que, em diversos momentos, seja por decisão política seja por condições materiais, a proteção do bem ambiental é deixada em segundo plano (REIS NETO, SILVA, ARAÚJO, 2016).

De maneira congruente com seu aspecto material exposto nos primeiros artigos, os objetivos específicos se revelam plenamente voltados 
para o enfoque econômico do meio ambiente. Preceitos como "I - criar instrumentos econômicos, financeiros e fiscais, para a promoção dos objetivos, diretrizes, ações e programas previstos nesta Lei" "II - fomentar a criação de instrumentos de mercado para a mitigação das emissões de GEE ", "XIV - promover padrões sustentáveis para atividades agropecuárias à luz das considerações sobre a mudança do clima" e "XVI - promover um sistema de pagamentos por serviços ambientais" mostram a presença de objetivos estritamente ligados a uma visão baseada no princípio do protetor-recebedor descrito por Sirvinskas (2017).

Ademais, as estratégias adotadas pela Política são reveladas de acordo com o setor econômico da atividade. Divididos em quatorze seções (1-Energia, 2-Transporte, 3-Industrial e Mineração, 4-Setor Público, 5- Agropecuária, 6-Biodiversidade e Florestas, 7-Recursos Hídricos, 8-Resíduos e Consumo, 9- Construção Civil, 10- Saúde, 11-Oceano e Gestão Costeira, 12-Semiárido e Desertificação, 13-Uso do solo e cobertura vegetal urbana, 14 - Instrumentos de Comando e Controle), os mecanismos previstos impõem ao Governo Estadual desde ações ligadas à educação ambiental voltada para a coletividade até a investigação e monitoramento dos fatores de risco à vida e à saúde decorrentes da mudança do clima. Outrossim, as estratégias mencionadas na norma incorporam o ideal do Poder Público como o principal agente responsável pela efetividade das ações, deixando a coletividade e o setor privado como meros receptores de comandos advindos do poder emanado pela Administração.

No capítulo referente aos instrumentos, divididos por tipologia (1- Plano Estadual de Mudanças Climáticas; 2-Instrumentos de Informação e Gestão; 3- Instrumentos Econômicos e Fiscais; 4- Projetos de Mitigação de Emissões de Gases de Efeito Estufa; 5- Licitações Sustentáveis; 6Educação, Pesquisa, Comunicação e Disseminação; 7-Defesa Civil; 8- Recursos Financeiros para Ações de Enfrentamento às Mudanças Climáticas e Serviços Ambientais), diferentemente do que ocorre em outras leis ambientais, como a Política Nacional do Meio Ambiente (Lei Federal $\mathrm{n}^{\circ}$ 6.938/81), o referido capítulo não traz apenas instrumentos pontuais (Licenciamento Ambiental, Avaliação de Impactos Ambientais) mas, sim, verdadeiras diretrizes de efetivação dos objetivos específicos previstos anteriormente.

Em razão da proposta inicial da presente pesquisa, o foco será dado no instrumento que define um verdadeiro organograma de implementação da política como um todo, "visando fundamentar e 
orientar a implantação da PEEMC de longo prazo, com horizonte de planejamento compatível com o período de implantação de seus programas e projetos" (PERNAMBUCO, 2010).

O Plano Estadual de Mudanças Climáticas apresenta três linhas básicas de metas a serem alcançadas no decorrer de seis anos, a partir da sua promulgação: metas obrigatórias, metas gerais e metas setoriais. As metas obrigatórias estão previstas no art. 23 da PEEMC. Possuem essa denominação pois fundamentam e orientam a implantação da política; basicamente, são as estruturas basilares que têm como escopo alicerçar o substrato básico do diploma legal. São consideradas o conteúdo infinitesimal a ser efetivado; o verdadeiro mínimo existencial da concretização da política (PERNAMBUCO, 2011).

Dentre as metas obrigatórias, no total de nove, merecem destaque quatro, em razão do seu potencial de ação: o diagnóstico da situação atual das mudanças climáticas no Estado, contendo o mapeamento das vulnerabilidades e suscetibilidades aos impactos esperados; inventário da contribuição do Estado para a emissão brasileira dos gases de efeito estufa; zoneamento socioeconômico e ecológico de risco climático e o estabelecimento das diretrizes e critérios para os Projetos de Redução de Emissões pelo Desmatamento e Degradação Florestal (REDD).

No que cabe às metas gerais, estas foram concebidas através da definição dos seus componentes, eixos temáticos e áreas de atuação, buscando determinar ações para a implementação da PEEMC, de forma conectada com as demais políticas públicas ambientais de Pernambuco. A função dessas metas é propiciar uma conexão com outras políticas que tangenciam a problemática do clima, de modo a desenvolver ações integradas. Em relação aos componentes (Figura 1), eles se dividem em dois: adaptação e mitigação.

De acordo com a PEEMC, no seu art. $1^{\circ}$, inciso I, considera-se adaptação o "conjunto de iniciativas e estratégias que permitem a adaptação, nos sistemas naturais ou criados pelos homens, a um novo ambiente, em resposta à mudança do clima atual ou esperada" (PERNAMBUCO, 2010). Já mitigação, para efeitos da política estadual, no art. $1^{\circ}$, inciso $X$, considera-se a "ação humana para reduzir as emissões por fontes ou ampliar os sumidouros de gases de efeito estufa" (PERNAMBUCO, 2010). 
Figura 1:

Componentes, eixos e áreas de atuação do Plano Estadual do Clima.

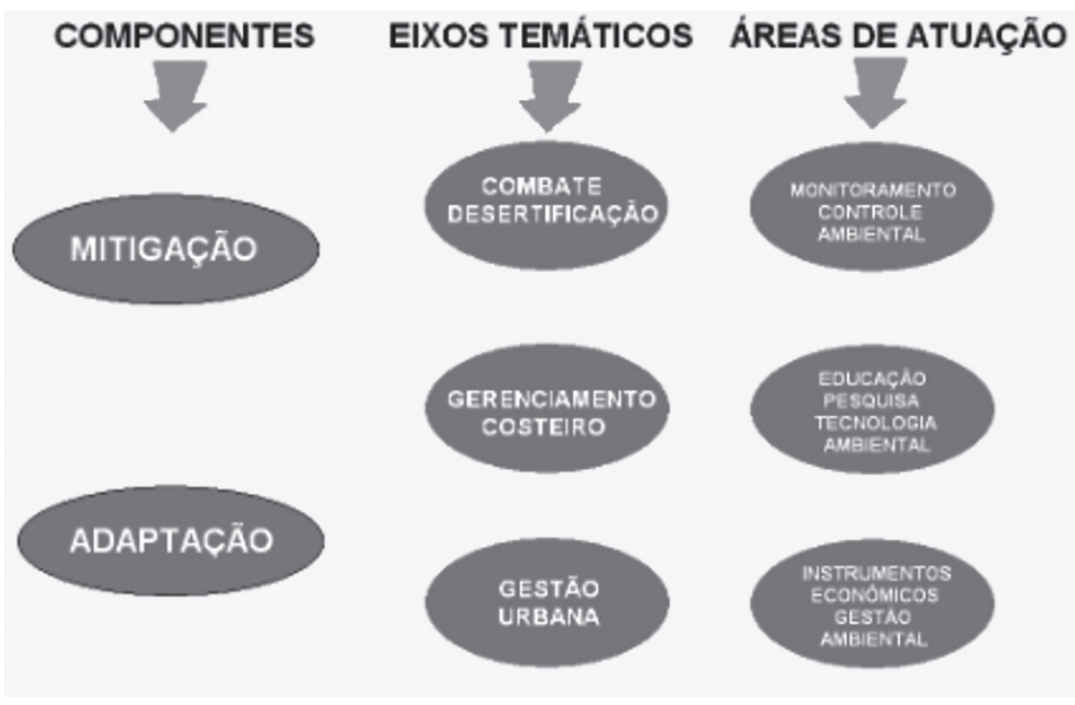

Fonte: Elaborado pelo autor.

Os eixos temáticos propostos dividem-se em 3: combate à desertificação; gerenciamento costeiro e gestão urbana. Por fim, em relação à área de atuação, que pode ser entendida como o meio pelo qual se pretende instrumentalizar os objetivos propostos, são sistematizados em três grupos: monitoramento/controle ambiental; educação, pesquisa e tecnologia ambiental; e instrumentos econômicos/gestão ambiental. Nessa divisão, ficam claros os enfoques dados pelo Governo Estadual. No primeiro momento (monitoramento/controle ambiental), constatamse os instrumentos diretamente ligados ao poder de polícia ambiental estatal, que consiste na faculdade de que dispõe a Administração Pública para condicionar e restringir o uso e gozo de bens, atividades e direitos individuais, em benefício da coletividade ou do próprio Estado (MILARÉ, 2013).

Para mais, a área de atuação denominada "educação, pesquisa e tecnologia ambiental" integra a necessidade de programas e ações voltadas ao desenvolvimento de iniciativas no campo do desenvolvimento tecnológico acerca de medidas que possam subsidiar a implementação da própria política. Nesse caso, de maneira cristalina, o Poder Público admite a necessidade de constante atualização e necessidade de integração entre 
os diversos atores envolvidos no avanço da política (Figura 2).

\section{Figura 2}

Recorte do cronograma previsto no Plano e a diversidade de atores envolvidos na implementação das metas.

\begin{tabular}{|c|c|c|c|c|c|c|c|}
\hline ADAPTAÇÃO: METAS MINIMAS PREVISTAS EM LEI ESTADUAL & & & & An & & & \\
\hline Atividades & Agentes Envolvidos & I & II & III & IV & $\mathbf{v}$ & VI \\
\hline $\begin{array}{l}\text { Revisăo do Zoneamento Ecológico Económico Costeiro -ZEEC - de } \\
\text { Pernambuco, incluindo os novos condicionantes decorrentes das Mudanças } \\
\text { Climáticas }\end{array}$ & $\begin{array}{l}\text { SEMAS, Prefeituras dos } \\
\text { Municipios Litorâneos, } \\
\text { Universidades, ONG'S }\end{array}$ & & & & & & \\
\hline $\begin{array}{l}\text { Elaborar o Zoneamento Ecológico Económico do semi-árido de Pernambuco, } \\
\text { incluindo as questôes decorrentes dos efeitos das Mudanças Climáticas }\end{array}$ & $\begin{array}{l}\text { SEMAS, EMBRAPA, } \\
\text { CONDEPE/FIDEM, } \\
\text { Universidades, ONG'S }\end{array}$ & & & & & & \\
\hline $\begin{array}{l}\text { Diagnóstico dos sistemas naturais das bacias hidrográficas de Pernambuco, } \\
\text { identificando as potencialidades e disponibilidades hídricas das bacias e sua } \\
\text { evoluçăo face aos cenários de aquecimento para os anos de 2020, 2030. } 2040 \\
\text { e } 2050 \text {. }\end{array}$ & $\begin{array}{l}\text { SEMAS, SRHE, CPRH, } \\
\text { Compesa, APAC, ANA, } \\
\text { CODEVASF, Universidades, } \\
\text { ONG'S }\end{array}$ & & & & & & \\
\hline $\begin{array}{l}\text { Identificação e Diagnóstico das áreas críticas de desertificação no território de } \\
\text { Pernambuco }\end{array}$ & $\begin{array}{l}\text { SEMAS, EMBRAPA, } \\
\text { Universidades, ONG'S }\end{array}$ & & & & & & \\
\hline $\begin{array}{l}\text { Elaboração do Mapa de Vulnerabilidade Ambiental do semi-árido de } \\
\text { Pernambuco }\end{array}$ & $\begin{array}{l}\text { SEMAS, EMBRAPA, } \\
\text { CONDEPE/FIDEM, } \\
\text { Universidades, ONG'S }\end{array}$ & & & & & & \\
\hline $\begin{array}{l}\text { Elaboração dos Mapas de Vulnerabilidade Ambiental dos municípios litorâneos } \\
\text { de Pernambuco }\end{array}$ & $\begin{array}{l}\text { SEMAS, Prefeituras dos } \\
\text { Municipios Litorâneos, } \\
\text { Universidades, ONG'S }\end{array}$ & & & & & & \\
\hline
\end{tabular}

Fonte: Adaptado pelo autor (PERNAMBUCO, 2011).

Resgatando a postura adotada ao longo da PEEMC e do próprio plano, os instrumentos econômicos/gestão ambiental demonstram a tendência, positiva e contemporânea, de minimizar os problemas ligados ao meio ambiente conjugando uma presença tanto nas ferramentas de comando e controle quanto nas de incentivo positivo, utilizando, para isso, mecanismos como a tributação ambiental, o pagamento por serviços ambientais, dentre outros (REIS NETO, SILVA, ARAÚJO, 2016).

Por fim, as metas setoriais nada mais são do que uma listagem do que se pretende implementar em diversos setores da sociedade que estão presentes na PEEMC, no capítulo referente às estratégias, como, por exemplo, setor de energia, setor de transporte, setor de biodiversidade e florestas.

No mais, o plano estabelece de uma forma geral conceitos muito abstratos e basicamente um cronograma das atividades relacionadas à política estadual. Não preza por uma facticidade. Quando traçadas, as metas não revelam como serão alcançadas. Apesar de tais situações que dificultam a aplicação do plano, este cumpre com o seu objetivo principal que é demonstrar quando será feita, teoricamente, cada etapa da Política Estadual. 


\subsection{Lei Estadual de Pagamentos por Serviços Ambientais de Pernambuco (Lei Estadual $n^{0}$ 15.809/16)}

Conforme o avanço da temática e a difusão de práticas que contribuem para a aplicação de conhecimentos ligados aos PSAs, o estado de Pernambuco, por meio de seu órgão central do Sistema Estadual de Meio Ambiente (SISEMA), qual seja, a Secretaria de Meio Ambiente (SEMAR), elaborou, com o objetivo de padronização das práticas/programas que possuem como fundamento o PSA, a Lei Estadual n ${ }^{\circ} 15.809 / 16$, também denominada Política Estadual de Pagamentos por Serviços Ambientais (PEPSA).

A principal função da referida lei é tentar conferir e fomentar, com o mínimo de segurança jurídica para o Estado e para os particulares envolvidos, a utilização do PSA como ferramenta de proteção ambiental. Não obstante tal objetivo mais genérico, logo no art. $2^{\circ}$, a norma traz os seguintes objetivos específicos in verbis:

Art. $2^{\circ}(\ldots)$ :

I - incentivar o mercado de serviços ambientais e reconhecer a sua valoração econômica e social;

II - incentivar a recuperação, a manutenção e a melhoria das condições de equilíbrio ecológico das áreas especialmente protegidas, em especial das áreas de reserva legal, de preservação permanente, das unidades de conservação, das áreas suscetíveis à desertificação, das áreas estuarinas, das zonas de recarga de aquífero e/ou de abastecimento de mananciais;

III - preservar, recuperar e/ou conservar o patrimônio ambiental do estado de

Pernambuco, para viabilizar a prestação de serviços ambientais pelos ecossistemas locais, observando-se as especificidades dos biomas Caatinga e Mata Atlântica com seus ecossistemas associados;

IV - promover projetos de Pagamento de Serviços Ambientais - PSA que beneficiem povos e comunidades tradicionais, definidos na forma do Decreto Federal $\mathrm{n}^{\circ} 6.040$, de 7 de fevereiro de 2007, assentamentos rurais e agricultores familiares, definidos na Lei Federal no 11.326, de 24 de julho de 2006, visando ao fortalecimento da sua identidade e respeito à diversidade cultural, com a conservação, preservação, uso sustentável e recuperação dos recursos naturais;

$\mathrm{V}$ - fomentar o mercado de serviços ambientais;

VI - dar consequência, no âmbito estadual, ao parágrafo 109 da decisão da $21^{\mathrm{a}}$ 
Conferência da Convenção-Quadro das Nações Unidas sobre Mudança do Clima, a COP 21, que se refere ao "reconhecimento do valor social, econômico e ambiental das atividades voluntárias de mitigação” (PERNAMBUCO, 2016).

Observa-se prima facie que a postura adotada pela referida norma foi o incentivo na utilização de mecanismos baseados no princípio de reforço positivo, qual seja, o protetor-recebedor, indo, consequentemente, ao encontro dos mais recentes acordos internacionais firmados na Conferência das Partes (COPs). Ademais, outro ponto que merece destaque é a fundamental participação dos diversos atores sociais nesse processo de implementação, consubstanciado no fortalecimento de projetos que possuem como foco os povos e comunidades tradicionais, além dos assentamentos rurais e agricultores familiares (art. $2^{\circ}$, IV).

Nesse sentido, sob o aspecto finalístico, a PEPSA adota uma visão pautada plenamente no desenvolvimento sustentável, conforme aduz Veiga (2010), pois preza por uma união entre o econômico (os valores monetários revertidos com o PSA), o social (a participação ativa das comunidades diretamente beneficiadas) e o ambiental (o manejo sustentável de espaços naturais, com a finalidade de conservá-los para as presentes e futuras gerações). Argumento que corrobora com tal afirmação é o reconhecimento e incentivo ao mercado de PSAs, tanto em razão da sua atuação econômica quanto pela sua vertente social (art. $\left.2^{\circ}, I\right)$. Outrossim, no que cabe ao patrimônio natural do Estado, a legislação reconheceu as especificidades inerentes às características dos diferentes biomas e a consequente necessidade de adaptação das metodologias de PSAs ao contexto local. Dessa maneira, alternativas como a REDD recebem o respaldo da PEPSA para fazer as modificações imperativas, sem desvirtuar os respectivos instrumentos, para ser mais bem-aplicada em Pernambuco (art. $2^{\circ}$, III).

Da mesma maneira, a política define como espaços-alvos (art. $2^{\circ}$, II) aqueles que o próprio ordenamento jurídico considera como sensíveis sob a ótica ambiental: áreas de reserva legal (Lei Federal $n^{0}$ 12.651/12 Código Florestal), de preservação permanente (Lei Federal no 12.651/12 - Código Florestal), das unidades de conservação (Lei Federal no 9985/00 - SNUC), das áreas suscetíveis à desertificação (Lei Federal nº 13.153/15 Política Nacional de Combate à Desertificação e Mitigação dos Efeitos da Seca), das áreas estuarinas (Lei Federal no 12.651/12 - Código Florestal), das zonas de recarga de aquífero e/ou de abastecimento de mananciais (Lei 
Federal n $\mathrm{n}^{\mathrm{0}}$ 12.651/12 - Código Florestal).

Com isso, a PEPSA, pelo menos no âmbito da legislação, pacifica as discussões sobre a denominada dupla proteção institucional conferida a essas áreas. $\mathrm{O}$ contrato de REDD, assim como outros instrumentos previstos na política, é uma forma alternativa para o cumprimento das metas de redução de carbono e da proteção ambiental. Assim, além da clássica utilização do "comando e controle", que tem como função a indicação dos comportamentos legais e ilegais, instrumentos econômicos pela via do mercado ou por outras vias têm sido utilizados. Trata-se de forma inovadora no Direito Ambiental, pois permite a configuração de uma espécie de mercado que promove a participação privada diretamente na contribuição para a eficácia jurídica da realização do interesse público geral.

Os PSAs integram uma interpretação econômica da natureza, na medida em que utilizam conceitos de mercado, a ideia de capital natural e de produtores de serviços ambientais. Utilizam ainda uma lógica de custo de oportunidades, avaliando monetariamente as situações de se manter a floresta em pé. São instrumentos estratégicos que podem contribuir com a melhoria da eficácia jurídica da proteção ambiental

Essa abordagem, contudo, ao mesmo tempo em que inova, é criticada por incentivar a mercantilização da natureza e por enfatizar a possibilidade de uma falta de ética ambiental no tratamento econômico dos recursos naturais. Essa interpretação também pode ser aplicada, na medida em que a cultura e o modo de vida dos povos que se utilizam desses recursos naturais também se tornam passíveis de negociação, caso não sejam respeitados de modo expresso pelo contrato firmado entre as partes.

Porém, a partir de um olhar técnico, tem-se construído, no Direito, a noção de que não se trata de um mercado de biodiversidade, mas sim de um mercado da obrigação jurídica de compensação, visto que esta foi a demanda criada pelo estado, que obriga a compensação das emissões de carbono. Torna-se, assim, um mercado de obrigações, ou um mercado de compensação, no lugar da mercantilização da natureza, conforme as principais críticas afirmam.

Outro ponto controverso é o conceito de adicionalidade. Para que esta ocorra, deve haver diferença no que ocorreria na linha de base ou ausência do projeto (também chamado "negócios como sempre"). Se não houver esta diferença, não ocorreu tal fenômeno. A linha de base é o que ocorre na ausência de um projeto de REDD, e a adicionalidade é a 
diferença, comparada à linha de base, correspondente ao que se deixa de emitir à atmosfera com o projeto (FERENCZY, 2009). Como observou Angelsen (2008), para a REDD ser efetiva e, consequentemente, seus objetivos serem alcançados, as reduções de emissões devem ser adicionais. Portanto, para o autor, deve ser feito uma "presunção realista do que ocorreria sem o projeto de REDD” (ANGELSEN, 2008).

Tomando como base esse argumento de Angelsen (2008), Ferenczy (2009) entendeu que as áreas de preservação permanente e as reservas legais não podem ser consideradas espaços aptos ao desenvolvimento de projetos de REDD, por consistirem em espaços que, por força de lei, não podem ser desmatados, não ocorrendo, portanto, a adicionalidade, caso fossem desenvolvidos projetos nesses espaços.

Neste ponto, Karousakis (2009) observou que, para efetivamente ocorrer redução de emissões por desmatamento e degradação, os incentivos financeiros devem ser direcionados às áreas que estejam em risco de serem convertidas a usos alternativos do solo. Salienta-se, no entanto, que esta identificação de áreas que estejam em risco não implica necessariamente a exclusão de áreas protegidas, já que projetos de REDD podem ser desenvolvidos em áreas protegidas que estejam sendo mal manejadas, sofrendo com falta de recursos e, portanto, não se desincumbindo com êxito na proteção dos processos ecológicos essenciais. O fator adicionalidade estaria, portanto, nesta situação, também presente (KAROUSAKIS, 2009).

Neste ponto merecem destaque as constatações da International Union for Conservation of Nature (IUCN):

Atualmente, muitas áreas protegidas são mal manejadas ou existem apenas no papel; estas áreas se incluem nas estatísticas nacionais de conservação da natureza, mas falham em prover os benefícios geralmente associados às áreas protegidas. Melhorar a efetividade de áreas protegidas se torna, assim, um objetivo-chave. (IUCN, 2010, p.12)

Ora, admitir que toda área protegida não sofre nenhum tipo de pressão, seja essa de cunho político, social ou econômico, é, na verdade, acreditar na plena eficiência das leis e das políticas governamentais de conservação. Infelizmente, tal situação não ocorre. Os problemas vão desde a falta de fiscalização até a falta de conscientização da própria sociedade. Entende-se que o posicionamento de Karousakis (2009) é o mais acertado, tendo em vista que, com este, seria possível abranger um maior número de 
espaços territoriais e, além disso, envolver diretamente a população.

Não existe dúvida de que a obrigação de conservar deveria ser cumprida sem precisar de nenhum tipo de incentivo econômico; todavia, os resultados apresentados não parecem satisfatórios, no que cabe à conservação da Caatinga e Mata Atlântica (SOS MATA ATLÂNTICA; INPE 2015; PERNAMBUCO, 2011), cabendo, portanto, uma discussão mais ampla sobre outras alternativas ligadas aos PSAs.

Atento a esta situação, o legislador assumiu um posicionamento expresso no que cabe às áreas que podem receber os projetos da REDD. De acordo com o art.13, $\S 4^{\circ}$, somente são elegíveis as áreas preservadas além do mínimo estabelecido pela legislação florestal nacional e estadual, em particular além das áreas de preservação permanente e da reserva legal compulsória, e com uso voluntariamente restringido por meio de servidão florestal, instituição de reserva particular do patrimônio natural ou averbação de reserva legal além do mínimo legal (PERNAMBUCO, 2016). Portanto, o sistema jurídico pernambucano adotou o posicionamento de Ferenczy (2009).

Para consecução dos objetivos propostos, foi necessária a criação de um arcabouço jurídico e institucional (Figura 3) no qual fosse clara a definição de atribuições para todos os órgãos envolvidos. Como órgão responsável pela arquitetura estadual na seara ambiental e pela sua própria atribuição no SISNAMA e no SISEMA, a função de planejamento, coordenação e controle da implementação é da Secretaria Estadual de Meio Ambiente e Sustentabilidade (SEMAS) (art. $5^{\circ}$ ).

A SEMAS, segundo definição da política, também possui como competência: (I) acompanhar as ações para atendimento das diretrizes da PEPSA; (II) articular ações nas diferentes instituições governamentais; (III) apoiar a realização de estudos, pesquisas e ações; (IV) disponibilizar e manter atualizadas as informações acerca das áreas contempladas com os projetos de PSA, assim como os serviços prestados por essas áreas e o valor percebido pelo beneficiário a título de remuneração; (V) garantir a transparência e o controle social dos programas, subprogramas, planos de ação e projetos de PSA; (VI) implementar o cadastro das áreas prioritárias para projetos de PSA e (VII) aprovar atos normativos voltados ao disciplinamento das ações. 
Figura 3: Arranjo institucional da PEPSA

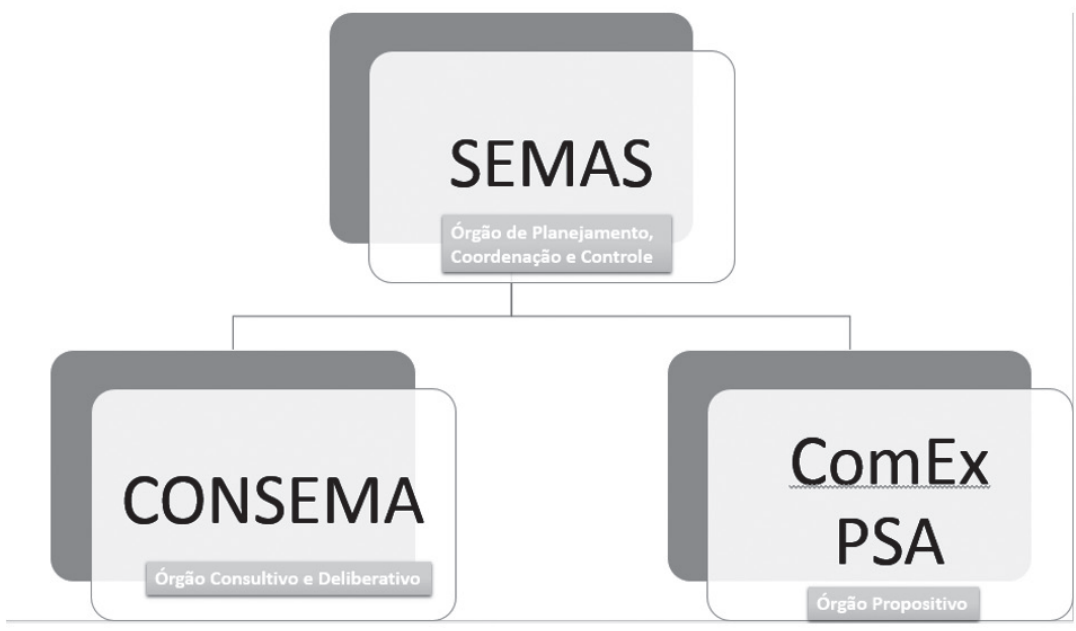

Fonte: Elaborada pelo autor.

É evidente, pelas disposições normativas, que, ao conferir as atribuições acima elencadas, o legislador optou por criar um verdadeiro órgão diretivo na implementação da PEPSA; contudo, é importante não olvidar que, em razão dos princípios do Direito Ambiental, como da informação e da participação popular, a SEMAS não possui a ratio decidendi absoluta, podendo suas decisões serem revistas de ofício (autotutela) ou até mesmo como provocação ao poder judiciário.

Devido ao seu caráter pioneiro na ordem legal, assim como em razão da lacuna existente no organograma ambiental do estado, fez-se mister a criação de um organismo com caráter propositivo que atuasse em harmonia com a Secretaria de Meio Ambiente e que tivesse como principal característica a composição heterogênea e interinstitucional dos seus participantes, o denominado Comitê Executivo do programa estadual de PSA (ComEx PSA).

A formação desse comitê é regulamentada pelo Decreto $n^{\circ}$ 43.128/2016 e compreende um representante e um suplente dos seguintes órgãos: (I) Secretaria de Meio Ambiente e Sustentabilidade; (II) Agência Estadual de Meio Ambiente-CPRH; (III) Secretaria de Desenvolvimento Econômico; (IV) Agência de Desenvolvimento de Pernambuco-ADDIPER; (V) Agência Estadual de Águas e Clima - APAC; (VI) Secretaria de Agricultura e Reforma Agrária; (VII) Instituto Agronômico de 
Pernambuco - IPA; e (VIII) Secretaria de Ciência, Tecnologia e Inovação. A preocupação na criação desse órgão foi garantir a participação das diferentes esferas do Poder Público executivo, levando em consideração órgãos basilares da seara econômica e da proteção ambiental, além de também incluir setores da agrícola e da ciência e inovação. A coordenação do comitê fica sob responsabilidade da SEMAS. Cabe salientar que, por meio da coordenação, é possível convidar pessoas e representantes de outras instituições a fim de participarem de atividades consideradas relevantes para o cumprimento de suas atribuições.

Nesse sentido, como afirmado alhures, o ComEx PSA tem como caráter marcante seu viés propositivo, tendo em vista que sua principal função é definir e propor ao Conselho Estadual de Meio Ambiente (CONSEMA) critérios e parâmetros para implementação do PSA, como, por exemplo, critérios de cálculo e forma de remuneração a ser paga aos provedores, considerando-se a importância do serviço ambiental prestado, a extensão da área, a condição socioeconômica do beneficiário, entre outros parâmetros definidos em regulamento (art. $6^{\circ}$, II), e os parâmetros técnicos e científicos a serem utilizados na avaliação e monitoramento dos serviços ambientais passíveis de remuneração (art. $6^{\circ}$, IV).

$\mathrm{O}$ terceiro órgão participante do arranjo institucional para implementação da PEPSA é o CONSEMA (art. $7^{\circ}$ ). Este possui caráter consultivo e deliberativo, assumindo um lugar de protagonismo, pois é ao conselho que cabe a análise das propostas criadas pelo ComEx PSA. De acordo com a PEPSA, o CONSEMA possui como atribuições: (I) analisar e deliberar sobre os critérios e parâmetros definidos pelo Comitê Executivo para os subprogramas e projetos de PSA; (II) aprovar a prestação de contas dos dispêndios realizados pelo Fundo Estadual de Pagamento por Serviços Ambientais; e (III) fixar normas complementares, sempre que necessário. Cabe salientar que as câmaras técnicas do CONSEMA poderão ser convocadas para subsidiar tecnicamente as deliberações do referido conselho, bem como propor alternativas para melhoria das ações de implementação da política e dos subprogramas de PSA.

Esse tridente institucional é responsável pela efetivação da PEPSA e, para tanto, também foram criados os instrumentos para consecução dos objetivos previstos no art. $2^{\circ}$ : (I) Programa Estadual de Pagamento por Serviços Ambientais; (II) cadastro estadual de Áreas Prioritárias para PSA; (III) inventário do capital natural do estado; (IV) sistema estadual de informações sobre PSA; (V) Fundo Estadual de Pagamento por Serviços 
Ambientais.

O Programa Estadual de PSA tem como objetivo implementar a política de PSA para a preservação, a conservação e a recuperação dos ecossistemas, e a manutenção e incremento da oferta dos serviços ambientais e ecossistêmicos (art. $9^{\circ}$ ). Essa é uma ferramenta macro que abriga cinco subprogramas, quais sejam: (I) Subprograma PSARestauração; (II) Subprograma PSA Biodiversidade; (III) Subprograma PSA Água; (IV) Subprograma PSA Carbono; (V) Subprograma PSA Beleza Cênica.

Os subprogramas são verdadeiras linhas de ações temáticas que vão balizar o contrato de PSA, assim como seus requisitos. Ou seja, os critérios para o PSA Biodiversidade e o PSA Água, por exemplo, são diferentes e possuem regulamentações distintas; contudo, nada impede que em uma mesma localidade seja incluída em mais de um subprograma, desde que os requisitos de ambos sejam cumpridos. Em razão do objetivo da presente pesquisa, apenas será analisado o PSA Carbono.

O subprograma PSA Carbono vem disciplinado no art. 13 e apoia projetos voltados a reduções ou sequestro comprovados de emissões de GEE, efetuados por aqueles que desenvolvam ações de mitigação de emissões de GEE oriundas de (I) desmatamento e degradação, bem como a manutenção e aumento dos estoques de carbono florestal (REDD+);

(II) agricultura e pecuária; (III) energia; (IV) transportes; (V) indústria; (VI) gestão de resíduos. O arranjo institucional do PEPSA promoverá a compensação de emissões provenientes de atividades produtivas, através de arranjos locais, sem prejuízos para eventuais acordos dentro das normatizações dos mercados convencionais ou voluntários (art. $\left.13, \S 1^{\circ}\right)$. Nesse sentido, será dada prioridade para projetos que envolvam comunidades ou populações tradicionais, assim como aquelas que envolvam assentamentos rurais.

Outro critério definidor na escolha das áreas receptoras é a priorização daquelas que, por critérios técnicos e legais, tais como tamanho, status de conservação e regime de uso sejam mais restritivas em termos de conservação (Art. $13, \S 2^{\circ}$ ). Logo, se houver apenas recurso para implementar o PSA em apenas um espaço e exista a concorrência de mais de um, será beneficiado aquele que reúna essas características de forma isolada ou cumulativamente.

Outrossim, cabe uma ressalva no que tange aos espaços elegíveis. Somente são aptos para o Subprograma PSA Carbono as áreas preservadas além do mínimo estabelecido pela legislação florestal nacional 
e estadual, em particular além das áreas de preservação permanente e da reserva legal compulsória, e com uso voluntariamente restringido por meio de servidão florestal, instituição de reserva particular do patrimônio natural ou averbação de reserva legal além do mínimo legal (art.13, §4 $4^{\circ}$.

Outra vedação que se dá em relação ao PSA Carbono é a utilização de áreas com florestas plantadas com espécies exóticas. Tal exclusão serve para resguardar as áreas nativas ou em recuperação e evitar que esses espaços sejam desmatados para, em seu lugar, ocorrer o plantio de espécies como o eucalipto e o pinus, ambos de rápido crescimento. Com isso, evita-se um estimulo ao plantio desenfreado dessas espécies em busca de um suposto sequestro de carbono desses espaços. Ora, como o próprio objetivo da PEPSA prega, o fim desta reside na manutenção dos espaços naturais conjuntamente com o manejo e recuperação destes.

Portanto, A PEPSA demonstra que existe um ambiente planejado e estruturado não somente para implementação da REDD, mas, para qualquer iniciativa que tome como base o conceito de PSA, pois, além de trazer requisitos claros para implementação, traz consigo critérios de elegibilidade para os projetos que se deseja incluir na proteção legal da política.

\section{CONCLUSÃO}

O Direito mostra-se peça fundamental no processo de utilização dos recursos naturais, pois é capaz de criar/legitimar o ambiente institucional e coordenar mecanismos que viabilizem a convivência pacífica entre interesses econômicos e a necessidade de preservação ambiental, não apenas com sua função sancionatória, mas, sobretudo, quando se assume uma postura promocional (protetor-recebedor). Nesse sentido, às Ciências Jurídicas, juntamente com os outros campos do saber, recai o papel de estruturar os mecanismos de PSA, de modo a respeitar a visão ecossistêmica e, ao mesmo tempo, se adequar às modificações da realidade que o envolve. Essa mutabilidade dos sistemas legais é evidente na proteção do bioma Caatinga.

Nesse entoada, se faz imperioso que Pernambuco, por meio dos seus órgãos governamentais, crie um ambiente jurídico consistente, suportando essas variações institucionais e valores individuais, mas que, ao mesmo tempo, permita a instituição de mecanismos que se adéquem aos anseios dessa sociedade. Essa base, de acordo com a lógica do 
desenvolvimento sustentável, deve ser a proteção ao meio ambiente, e as engrenagens flexíveis e adaptáveis são os instrumentos que protegem e promovem os aspectos sociais e econômicos, de maneira harmônica e sistêmica.

Essa função é atribuída à REDD, tendo em vista todo o arcabouço jurídico legal desenvolvido para sua implementação no estado. Desde a definição de objetivos até a criação de um arranjo institucional favorável, esse sistema vem ocupar uma lacuna existente não só no plano legal mas, também, na realidade que outrora era caracterizada pela falta de eficácia dos instrumentos de comando e controle.

Destarte, posto esse cenário, a REDD desponta como uma ferramenta bastante útil para trazer melhorias não só no âmbito jusambiental, mas, também, para exigir uma postura ambientalmente correta de toda a sociedade. Seu fundamento tem por base não só as disposições legais estaduais, como, também, as diretrizes nacionais e convenções/tratados internacionais. Logo, sob o ponto de vista jurídico, o mecanismo pode ser implementado em Pernambuco para conservação da Caatinga.

\section{REFERÊNCIAS}

AMORIM, Fernando Sérgio Tenório de; BARROS, Hugo Marinho Emídio de. Dignidade Humana, Segurança Nacional e os Refugiados Ambientais na Lei 9.474/1997. In: Revista Veredas do Direito, Belo Horizonte, v. 14, n. 28, p. 93-126, jan./abr. 2017. Disponível em: <http://www.domhelder. edu.br/revista/index.php/veredas/article/view/914>. Acesso em: 05 abril 2018.

ANGELSEN, A. (ed.). Movingaheadwith REDD: Issues, options and implications. Bogor, Indonesia: CIFOR, 2008. ., et al. (eds.) Realising REDD+.national strategy and policy options. Bogor, Indonesia, CIFOR, 2009.

BEGOSSI, A. Extractive reserve in the Brazilian Amazon: an example to be followed in theAtlantic Forest? Ciência \& Cultura, vol. 50, n. 1, p.2428, 1998.

BOYD, J.; BANZHAF, S. What are ecosystem services? The need for standardized environmental accouting units. In: Ecological Economics, v.63, p. 616-626, 2007 
BRASIL. Constituição Federal da República Federativa do Brasil de 1988. Disponível em $<$ https://www.planalto.gov.br/ccivil_03/constituicao/ ConstituicaoCompilado.htm> . Acesso em 18 de fev. de 2017

CUNHA, T.F. O REDD como instrumento econômico de concretização do desenvolvimento sustentável na Amazônia brasileira. In: BENJAMIN, A.H.; LECEY, E.; IRIGARAY, C.T.S.H PNMA: 30 anos da Política Nacional de Meio Ambiente. São Paulo: Imprensa Oficial do Estado de São Paulo, 2011.

CONSTANZA, R.; DALY, H.; BARTHOLOMEW, J. Goals. Agenda and Policy Recommendations for Ecological Economics. In: COSTANZA, R. Ecological Economics: The Science and Management of Sustainability. New York, Columbia University Press, 1991.

DALY, H.E; FARLEY, J. Ecological economics: principles and applications. Washigton DC: Island Press, 2004.

DIEGUES, A.C. O mito moderno da natureza intocada. São Paulo: NUPAUB, 1994.

FERENCZY, M. A. V. H. Direito Ambiental: Potencial do REDD+ para a sustentabilidade. Curitiba: Juruá: 2012

FIORILLO, C.A.P. Curso de Direito Ambiental Brasileiro. 15 ed. São Paulo: Saraiva, 2014.

GRAINGER, A.; OBERSTEINER, M. A framework for structuring the global forest monitoring landscape in the REDD+ era. Environmental Science \&Policy, v. 14, p. 127-139, 2011.

HAYES, T.; PERSHA, L. Nesting local forest initiatives: revisiting community forest management in a REDD + world. Forest Policy and Economics, v. 12, n. 8, p. 545- 553, Oct. 2010

KAROUSAKIS, K. Promoting biodiversity co-benefits in REDD. Paris: OECD Environmental WorkingPapers. n.11, 2009.

LEDERER. M. From CDM to REDD+ - What do weknow for setting up effective and legitimate carbon governance. Ecological Economics, v. 70, p. 1900-1907, 2011.

LEFF, E. Racionalidade Ambiental: a reapropriação social da natureza. Rio de Janeiro: Civilização Brasileira, 2006. 
MARTÍNEZ-ALIER, J. Ecologismo dos pobres: conflitos ambientais e linguagens de valoração. São Paulo: Contexto, 2007.

MORAIS, Y.C.B.M; ARAÚJO, M.S.B; MOURA, M.S.B.;GALVÍNCIO,J.D.; MIRANDA,R.Q. Análise do Sequestro de Carbono em áreas de Caatinga do Semiárido Pernambucano. Revista Brasileira de Meteorologia, v. 32, n. 4, p. 585-599, 2017.

MILARÉ, É. Direito do Ambiente: Gestão Ambiental em foco. 8 ed. Rio de Janeiro: RT, 2013.

MURADIAN, R.; CORBERA, E.; PASCUAL, U.; KOSOY, N. MAY, P.H. Reconciling theory and practice. Analternative conceptual framework for understanding payments for environmental services. In: Ecologiacal Economics, v. 69, p.1202-1208, 2010.

NUSDEO, A.M. Pagamento por Serviços Ambientais: sustentabilidade e disciplina jurídica. São Paulo: Atlas, 2012.

NUSDEO, F. Desenvolvimento e ecologia. São Paulo: Saraiva, 1975

OLLIVIER, H. Growth, deforestation and the efficiency of the REDD mechanism. Journal of Economic and Management, v. 64, p. 312-327, 2012.

OST, F. The doctoral thesis in law: From the project to the defense. Revista de Estudos Constitucionais, Hermenêutica e Teoria do Direito, v. 7, n. 2, p. 98-116, mai./ago., 2015.

PERNAMBUCO. Lei $N^{o} 14090$ de 2010. Dispõe sobre a Política Estadual de Enfrentamento a Mudanças Climáticas, e dá outras providências. Disponível: <www.cprh.pe.gov.br/.../PLANO_MC_PERNAMBUCO>. Acesso em: 18 de set. de 2017.

SEMAS, 2011.

. Plano Estadual de Mudanças Climáticas. Recife:

REIS NETO, A.F.; SILVA, L.J.A.; ARAÚJO, M.S.B. Relatório de passivo ambiental: estudo de caso à luz da legislação, da doutrina e da jurisprudência ambientais brasileiras. Veredas do Direito, v. 13, n. 26, p. 141-166, mai./ ago. 2016.

Mata Atlântica pernambucana: argumentos jurídicos para implementação da R.E.D.D. Veredas do Direito, v. 14, n. 30, p. 143- 
168, set./dez. 2017.

ROTHENBURG, W. C. A Constituição Ecológica. In: KISHI, S. A. S.; SILVA, S. T. da; SOARES, I. V. P. (Org.). Desafios do Direito Ambiental no século XXI: estudos em homenagem a Paulo Affonso Leme Machado. São Paulo: Malheiros, 2005. p.813-831.

SIRVINSKAS, L.P. Manual de Direito Ambiental. 17 ed. São Paulo: Saraiva, 2017.

S.O.S MATA ATLÂNTICA; INSTITUTO NACIONAL DE PESQUISAS ESPACIAIS -INPE. Atlas dos remanescentes florestais da mata atlântica período 2013-2014. São Paulo: Fundação S.O.S Mata Atlântica, 2015.

VEIGA, J.E. Desenvolvimento sustentável: o desafio do século XXI. Rio de Janeiro: Garamond, 2010.

WUNDER, S. Payments for environmental services: some nuts and bolts. Jacarta: Center for International Forestry Research, 2005.

\section{Como citar este artigo (ABNT):}

REIS NETO, Afonso Feitosa; SILVA, Leônio José Alves da; ARAÚJO, Maria do Socorro Bezerra de. SISTEMA JURÍDICO DA R.E.D.D NA CAATINGA PERNAMBUCANA. Veredas do Direito, Belo Horizonte, v. 15, n. 33, p. 291-319, set./dez. 2018. Disponível em: <http://www. domhelder.edu.br/revista/index.php/veredas/article/view/1278>. Acesso em: dia mês. ano.

Artigo recebido em: 07/09/2018

Artigo aceito em: 20/11/2018 